\title{
STUDY ON THE VEHICLE LINEAR DYNAMIC INTERVAL IN A TRAFFIC FLOW
}

\author{
Oleg Fyodorovich Danilov, Victor Ivanovich Kolesov, Denis Alexandrovich Sorokin*, Maxim Leonidovich Gulaev
}

Federal State Budget Educational Institution of Higher Education “Industrial University of Tyumen” (IUT), Tyumen, Russian Federation

*E-mail of corresponding author: sorokinda@tyuiu.ru

\section{Resume}

The transportation industry of a modern city involves the effective systems for the road traffic management. To manage any object is impossible without understanding its specifics. The tasks of road traffic management are based on mathematical models of traffic flows. The "following the leader" model based on the linear dynamic interval of vehicles has become widely accepted in the model analysis. The paper discusses the mathematical model of the linear dynamic interval of vehicles; the model is identified structurally and parametrically. Coefficients of the model are analyzed in detail; a generalized assessment of the dynamic performance of the traffic flow, evolved in various road conditions, is given. The study has resulted in the proposed basic models for traffic flows that can be used for algorithmic support of the model analysis of traffic flows and the road traffic management.

\section{Article info}

Received 8 March 2020

Accepted 11 July 2020

Online 13 November 2020

\section{Keywords:}

smart city,

dynamic interval,

traffic flow,

speed,

intensity,

density,

road coverage

ISSN 1335-4205 (print version)

ISSN 2585-7878 (online version)

\section{Introduction}

Strong promotion of the Smart City concept is a current trend in Russia. As a rule, the approach to growth strategy of cities is based on the idea of their sustainable development which is the systemic basis of "Smart Cities" [1-6]. The present Smart Cities include Smart Mobility as a key component; in here, in terms of importance, the "weight" of the component is estimated at no less than $20 \%$. The success in this field is achieved due to the depth of understanding of the technological process, the traffic flow (TF) being its "spring".

The authors have proposed a method that makes it possible to comprehensively assess efficiency of the traffic flows comprehensively [7]. Theoretical and experimental studies have been carried out based on the mathematical model of the TF developed by the authors and considered in detail in the reference [8]. The paper, being a logical continuation of the mentioned references, presents a comprehensive study of the linear dynamic interval (DI) of vehicles.

The "following the leader" model describes how a led vehicle reacts to a leading vehicle in a single lane. Over the past 60 years a large number of investigations have been made, the main purpose of which was simulation modelling of traffic flow [8-20]. Existing mathematical models have significant accuracy obtained during the continuous development of the subject domain at hand. However, there are some models' elements that require additional research and improvements of the mathematical representations.

\section{Dynamic performance study}

The dynamic interval is recorded as follows [21-23]:

$L(V)=m_{2} \cdot V^{2}+m_{1} \cdot V+m_{0}$,

where

$L$ - linear dynamic interval, $\mathrm{m}$;

$V$ - speed, m.s. ${ }^{-1}$;

$m_{2}$ - coefficient, $\mathrm{s}^{2} \cdot \mathrm{m}^{-1}$

$m_{1}$ - coefficient, $\mathbf{s}$;

$m_{0}$ - coefficient, $\mathrm{m}$.

The linear dynamic interval of a vehicle is widely used in mathematical modeling and represents the distance between the leading and led vehicles, ensuring the safe operation of the traffic flow.

This makes it possible to evaluate the density of the TF

$q(V)=1 / L(V)=1 /\left(m_{2} \cdot V^{2}+m_{1} \cdot V+m_{0}\right)$,

where

$q$ - density, TU.km ${ }^{-1}$

TU - traffic unit.

The basic equation of the $\mathrm{TF}$ [22-24] determines its intensity 


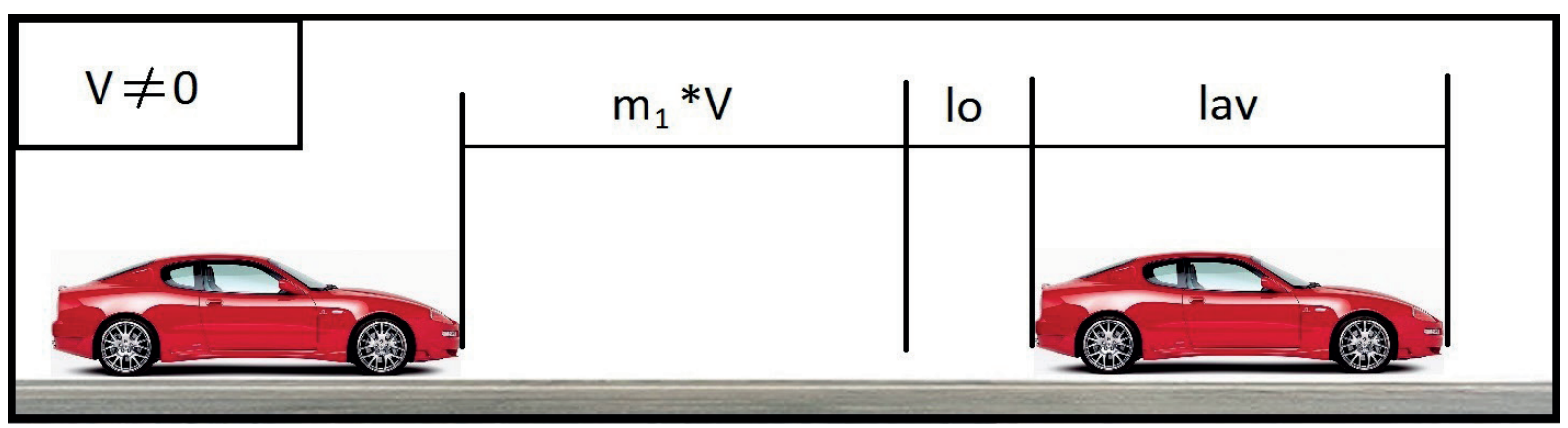

Figure 1 Interval determined between the two adjacent vehicles

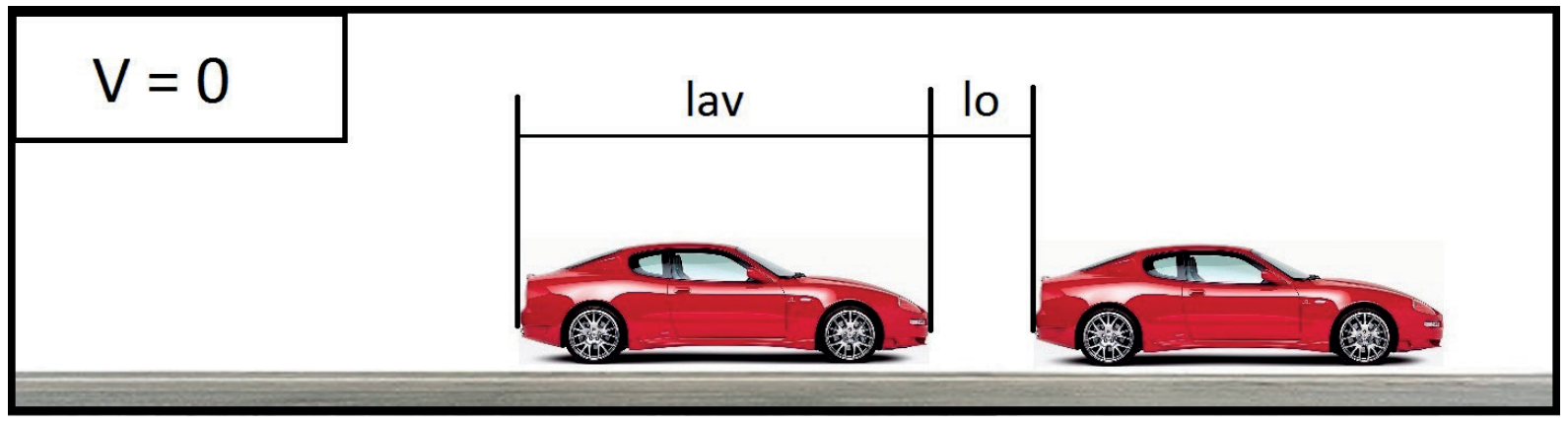

Figure 2 Minimum interval between the two adjacent vehicles in a traffic jam

$N(V)=V \cdot q(V)=V /\left(m_{2} \cdot V^{2}+m_{1} \cdot V+m_{0}\right)$

where

$N$ - intensity, TU.h ${ }^{-1}$.

The extreme point of intensity is reached when on the assumption $d N(V) / d V=0$. When considering Equation (3), one can find the derivative of the function with respect to speed

$$
\frac{\left(V^{2} \cdot m_{2}+V \cdot m_{1}+m_{0}\right)-V\left(m_{1}+2 \cdot V \cdot m_{2}\right)}{\left(V^{2} \cdot m_{2}+V \cdot m_{1}+m_{0}\right)^{2}}=0 .
$$

The root of equation corresponds to the speed of the maximum intensity

$$
V_{\max N}=\sqrt{m_{0} / m_{2}}
$$

The density reaches its peak when the traffic flow does not move, i.e. when $V=0$. Here, $L$ takes the minimum value $L_{\text {min }}=m_{0}$, which corresponds to the density

$$
q_{\max }=1 / m_{0} .
$$

Thus, the main dynamic characteristics of the $\mathrm{TF}$ are functionally related to the DI and, in fact, are evaluated by the coefficients included in Equation (1).

\section{Coefficient $m_{0}$ study}

Figure 1 shows the actual interval between two vehicles, which is the sum

$$
l_{0}+m_{1} \cdot V+l_{a v}
$$

where

$l_{0}$ - arbitrary interval, $\mathrm{m}$;

$l_{a v}$ - average length of the vehicle, $\mathrm{m}$.

The coefficient $m_{1}$ is characterized by the stopping time value and depends on the driver's response and the rapidity of the brake system [25-27]. The sum in Equation (6) is valid if the vehicles have the same values of deceleration developed by the brake system in operation. Then, when the "leading" driver slows down, the real interval between vehicles will be reduced by a distance $m_{1} \cdot V$.

Value of the interval $l_{0}$ depends on the "degree of cohesion" of the $\mathrm{TF}$ and is minimized in the maximum density. Figure 2 shows the flow as a "traffic jam" $(V=O)$. Here, $l_{0}$ can be defined as the minimum distance between vehicles, which ensures safety of the flow. In fact, if the "leading" driver slows down urgently, the TF transits from the state of movement (Figure 1) to the full stopping (Figure 2) and the interval $l_{0}$ remains the only obstacle for a vehicle collision.

Thus, the expression for the coefficient $m_{0}$ takes the form

$m_{0}=l_{a v}+l_{0}$,

where

$l_{a v}$ - average length of the vehicle, $\mathrm{m}$;

$l_{0}$ - safety interval between two vehicles in a traffic jam, m.

Taking into account Equations (1) and (7), the DI can be recorded as

$$
L(V)=m_{2} \cdot V^{2}+m_{1} \cdot V+l_{a v}+l_{0}
$$

It is necessary to note that $L$ in Equation (8) evolves into the classical interval of Tanaka - Equation (1) [21-22] 


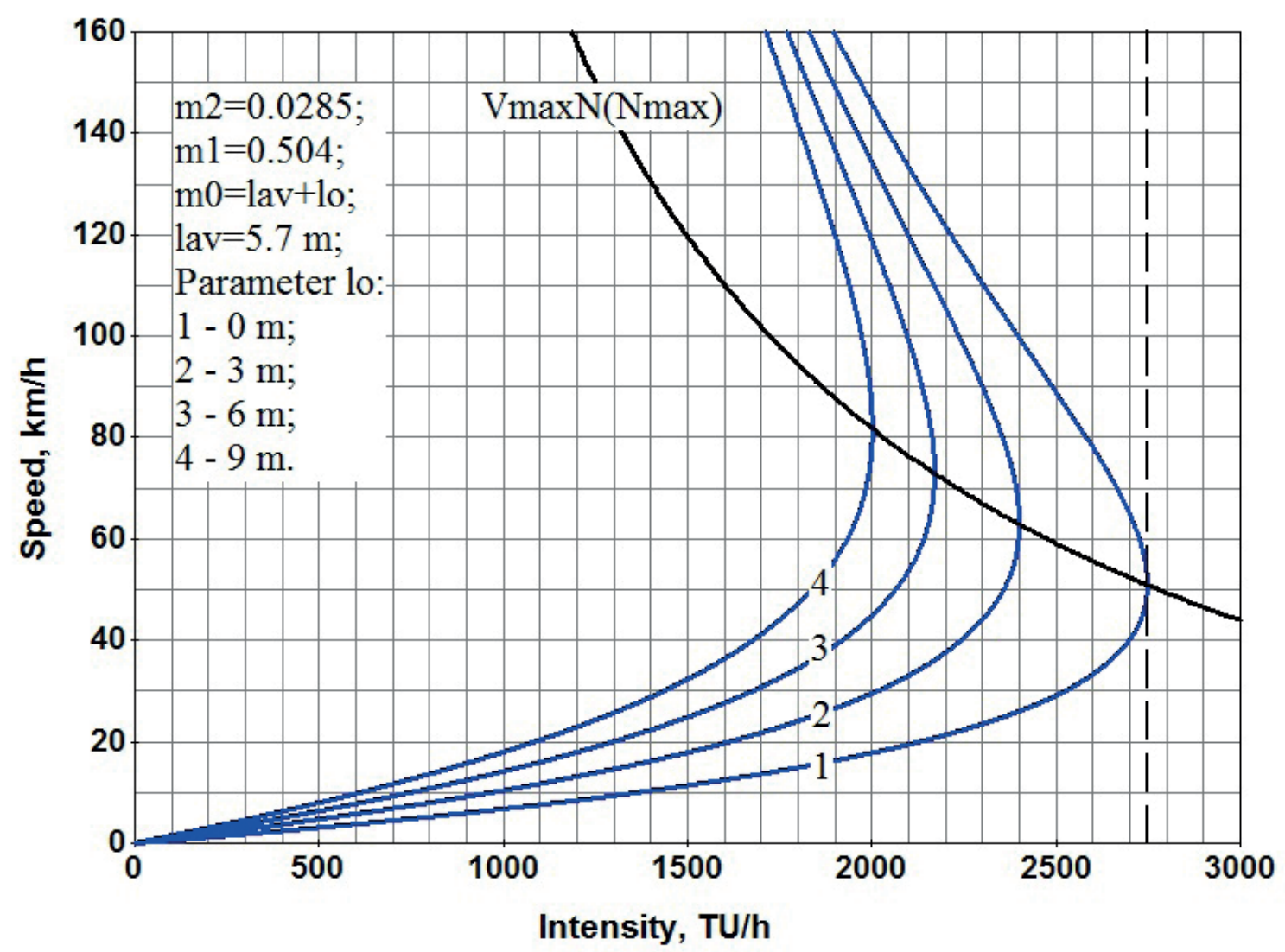

Figure $3 V_{\max }$ versus maximum intensity $N_{\max }$

if $l_{0} \rightarrow 0$ (in $l_{0}=0 m_{0}=l_{a v}$ ). In here, the changed dynamic performance of the TF results from direct connection of the values and $L$. To study the sensitivity of the extreme point intensity to value of $l_{0}$, Equation (4) is transformed, taking into account Equation (7), to

$V_{\max N}=\sqrt{\left(l_{a v}+l_{0}\right) / m_{2}}$.

In given values of $l_{a v}$ and $m_{2}$, it is easy to evaluate the following

$l_{0}=m_{2} \cdot V_{\max N}^{2}-l_{a v}$.

On the other side, from Equation (3) follows that

$$
l_{0}=V / N-\left(m_{2} \cdot V^{2}+m_{1} \cdot V+l_{a v}\right) .
$$

If to evaluate Equation (10) integrally, with Equation (11), provided that the real intensity corresponds to the maximum one, one obtains the equation

$$
\begin{aligned}
& m_{2} \cdot V_{\max N}^{2}-l_{a v}=V_{\max N} / N_{\max }- \\
& -\left(m_{2} \cdot V_{\max N}^{2}+m_{1} \cdot V_{\max N}+l_{a v}\right),
\end{aligned}
$$

from which one obtains

$$
V_{\max N}=\left(1 / N_{\max }-m_{1}\right) /\left(2 \cdot m_{2}\right) .
$$

The calculation data of Equation (12) are illustrated in Figure 3; in here, the parameters of the DI correspond to the Tanaka model for the standard road conditions [22] $\left(m_{2}=0.0285 ; m_{1}=0.504 ; l_{a v}=5.7 \mathrm{~m}\right)$.

If the interval $l_{0}$ increases, the position of the extreme point $N_{\max }$ drifts towards the increased speed $V_{\max }$, in here, the real value of the maximum intensity decreases. Analysis of Equation (12) suggests that the drift is sensitive to the parameters $m_{1}$ and $m_{2}$

The minimum interval $l_{0}$ is widely used in mathematical modeling of the TF, in particular in references [25, 27]. Impact of $l_{0}$ on the road safety can be assessed using the safety criterion $K_{s}$ proposed in [25]. The criterion takes the form

$$
K_{s}=\frac{m_{2} \cdot V^{2}+m_{1} \cdot V+l_{0}}{m_{2} \cdot V^{2}+m_{1} \cdot V} .
$$

Figure 4 illustrates the two operating modes of the flow. The upper curve illustrates the distance observed by the drivers as prescribed by $L$ with $l_{0}=0$. The maximum intensity $N_{\max }=2747$ TU.h ${ }^{-1}$ (point 1) is reached at $V_{\text {maxN }}$ $=51.61 \mathrm{~km} \cdot \mathrm{h}^{-1}$. The lower curve has been plotted taking into account $l_{0}=2.22 \mathrm{~m}$. Here, the position of the extreme point $N_{\max }=2475$ TU.h ${ }^{-1}$ (point 2) shifts to the maximum permissible speed limit in the city $-60 \mathrm{~km} \cdot \mathrm{h}^{-1}$. Performance of the safety criterion in the changed $V_{\text {max }}$ is shown in Figure 5. If $K_{s}=1$ at point 1 (in $l_{0}=0$ ), as it follows from Equation (13), then its value reaches $K_{s}=1.1359$ at point 2, i.e. the maximum provided $V \leq 60 \mathrm{~km} . \mathrm{h}^{-1}$.

Thus, to find a rational value of the interval $l_{0}$, the algorithmic support has been created; it suggests that 


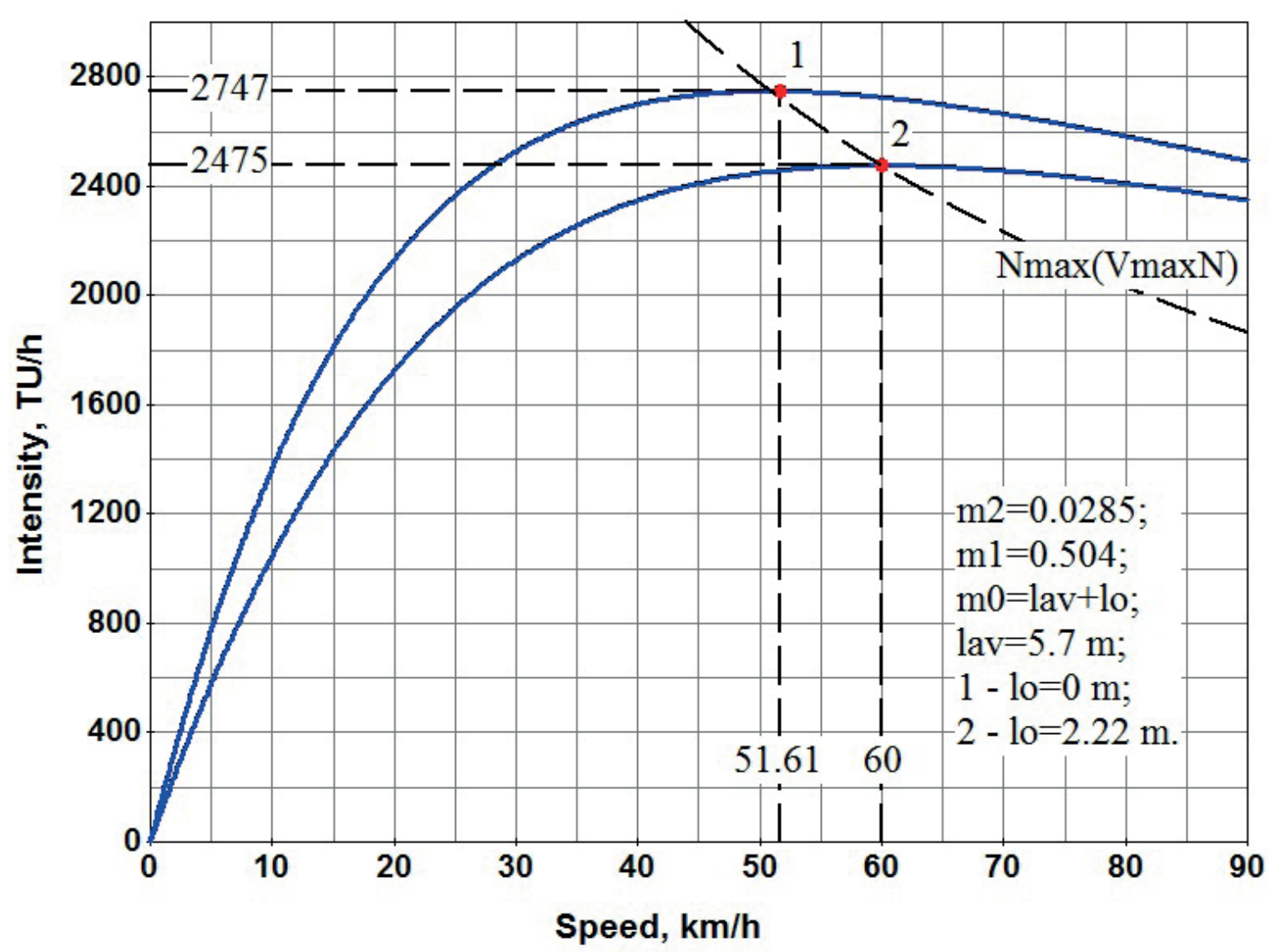

Figure 4 Analysis of the two operating modes of the TF

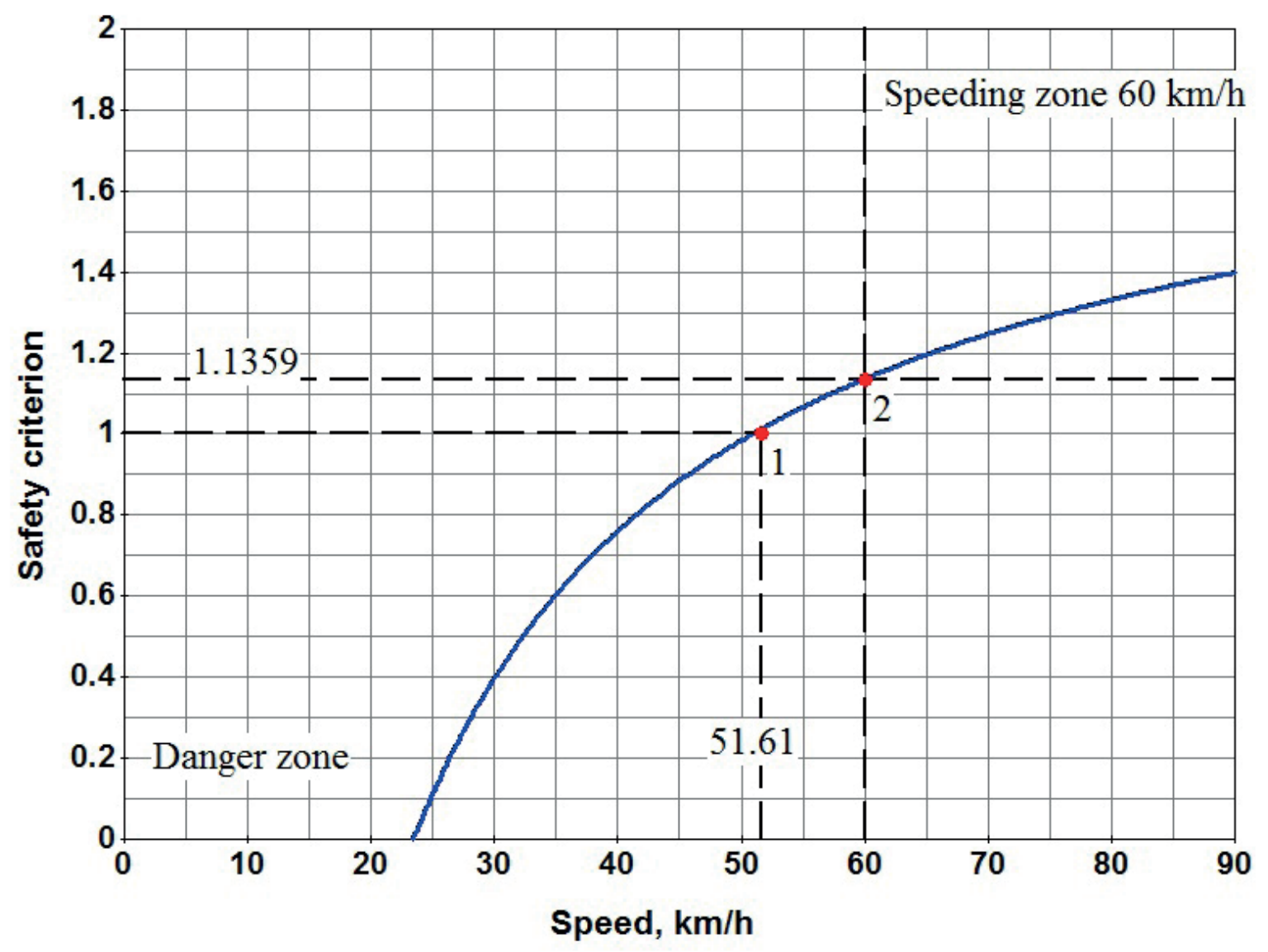

Figure 5 Safety criterion $K_{s}$ versus $V_{\operatorname{maxN}}$ 
Table 1 Confidential intervals of the driver's response for lognormal distribution

\begin{tabular}{ccc}
\hline $\begin{array}{c}\text { confidential interval reliability } \\
(\%)\end{array}$ & $\begin{array}{c}\text { case } 1 \\
\text { "unexpected obstacle" } \\
(\mathrm{s})\end{array}$ & $\begin{array}{c}\text { case } 2 \\
\text { "expected signal" } \\
(\mathrm{s})\end{array}$ \\
\hline 50 & 1.18 & 0.53 \\
85 & 1.87 & 0.64 \\
95 & 2.45 & 0.72 \\
99 & 3.31 & 0.82 \\
\hline
\end{tabular}

Table 2 Standards for effective braking of the TU with a brake system in operation when checking in the travel conditions

\begin{tabular}{ccc}
\hline TU & category of TU & rapidity of the brake system (max.), \\
\hline passenger and utility vehicles & $\mathrm{M} 1$ & 0.6 \\
trailer cars & $\mathrm{M} 2, \mathrm{M} 3$ & 0.8 \\
trucks & $\mathrm{M} 1$ & 0.6 \\
tractor-trailers & $\mathrm{N} 1, \mathrm{~N} 2, \mathrm{~N} 3$ & 0.8 \\
\hline
\end{tabular}

the maximum intensity is reached only in the interval 1-2 (Figure 4). On one side, this segment is limited by the "danger zone" (Figure 5); in here, $V_{\operatorname{maxN}}$ at point 1 is evaluated by Equation (9) in $l_{0}=0$. On the other side, $l_{0}$ is evaluated by Equation (10) in the permissible speed limit. The position of points 1 and 2 (Figure 4), relative to the axis of speed, is determined by the DI parameters and the value of the permissible speed limit in the city.

If it is possible to control the speed, then (within the search strategy for the value of $l_{0}$ ) two approaches are available: either to increase the safety of the flow and decrease its maximum intensity, or to increase $N_{\max }$ if the level of danger increases. Figure 4 illustrates the position of $N_{\max }$ at point 2 as the most preferable from the point of view of safety; in here, $l_{0}=2.22 \mathrm{~m}$ and it is an entirely "traditional" value. The minimum interval between the adjacent vehicles in a traffic jam is usually $l_{0}=1-3 \mathrm{~m}$ in mathematical modeling [27]. The average length of the TU is determined by structure of the $\mathrm{TF}$.

\section{Coefficient $m_{1}$ study}

When analyzing the stopping time, the rapidity of the brake system is usually taken into account alongside with the driver's response [25-27]. In here, the response is usually differentiated into two intervals: the deceleration of the brake system and increase of the deceleration time [26]. Thus, the coefficient $m_{1}$ can be represented as [25-26]

$m_{1}=t_{d r}+t_{b l}+0.5 \cdot t_{s i}$

where

$t_{d r}$ - driver's response, $\mathbf{s}$;

$t_{b l}$ - brake lag, i.e. deceleration of the brake system, s;

$t_{s i}$ - slow down increase, i.e. rise time of the deceleration, s.
The response time depends on a number of factors: the driver's qualification, his age and health, traffic conditions, etc. At present, there is no any strict specification of the $t_{d r}$ value; therefore, in assessing the brake system performance of the TU, the following ranges of possible values are used: in [26] $t_{d r}=0.3-2.5 \mathrm{~s}$, in [24] $t_{d r}=0.6-0.8 \mathrm{~s}$, in [27] $t_{d r}=$ $0.1-0.6 \mathrm{~s}$.

The report [23] presents results of experimental study obtained by Lerner. During the experiment, two situations were considered. In the first case, the driver did not know that an unexpected obstacle, which would make him to slow down, would arise in the way. In the second case, the driver expected a signal, but he did not know exactly when this would happen. The obtained confidential intervals, with the corresponding reliability indicators, are given in Table 1. Results of the study show that the driver's response is caused by the need to predict the travel conditions.

Deceleration of the brake system performance is determined by the time when the driver begins to slow down versus the time when deceleration begins; in here, the vehicle continues to move uniformly with the initial speed. Value of $t_{b l}$ depends on the type, design and physical situation of the brake system and varies in the average ranges: for a hydraulic drive gear $t_{b l}=0.1-0.4 \mathrm{~s}$ [26], $t_{b l}=0.05-0.15 \mathrm{~s}$ [24]; for a pneumatic drive gear $t_{b l}$ $=0.6-0.8 \mathrm{~s}$ [26], $t_{b l}=0.2-0.4 \mathrm{~s}$ [24]. For monorails with pneumatic drive gear, the deceleration time can reach $t_{b l}$ $=2-3 \mathrm{~s}$ [26].

The rise time of deceleration is characterized by a continuous increase in braking forces, which results in a fixed value of deceleration. Value of the $t_{s i}$ depends on the brake drive type, weight of the car and the adhesion coefficient. Generally, the time of blocking out is proportional to the weights falling upon the axles of the front and rear wheels [25]. On average, for a standard dry road coverage, $t_{s i}=0.4-0.6 \mathrm{~s}$ [24]. 


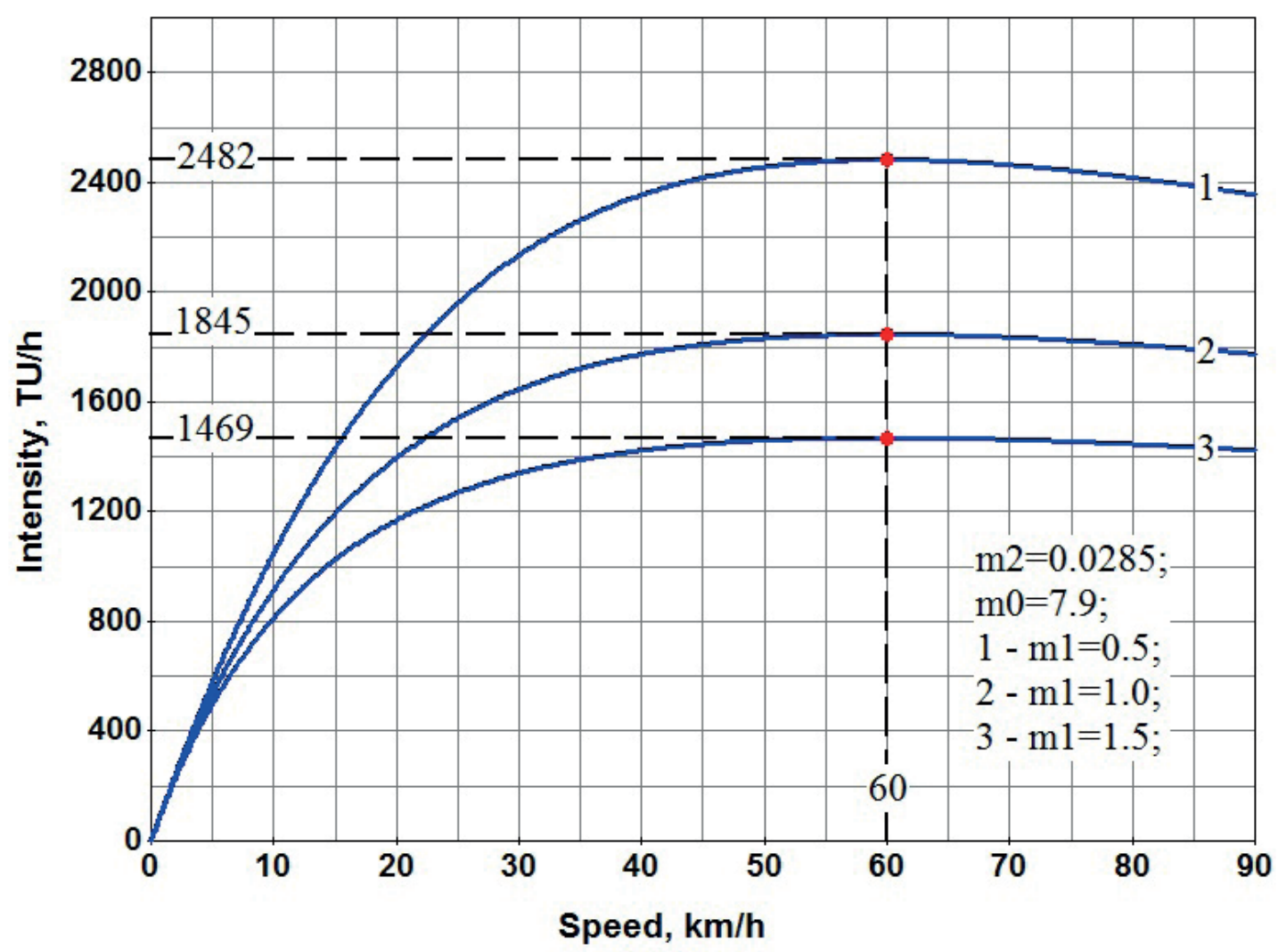

Figure 6 Position of the extreme point $N_{\max }$ versus $m_{1}$

The standards for effective braking of the TU, with a brake system in operation, are regulated by the GOST [28]. The maximum permissible values of the brake operation, when checking in the travel conditions, are shown in Table 2.

As for the effect of $m_{1}$ on the dynamic characteristics of the TF, $L$ increases if the value of $m_{1}$ increases, as can be seen from Equation (1), and the density decreases at a fixed speed, as shown in Equation (2). The intensity versus speed, with a changing value of $m_{1}$, is illustrated in Figure 6 . The speed $V_{\operatorname{maxN}}$ remains constant, which is due to the no effect of $m_{1}$ on $V_{\max N}$ in Equation (4) and the maximum intensity decreases if $m_{1}$ increases. In here, the real value of $m_{1}$ can be evaluated using Equations (12) and (4), and the simultaneous solution results in the expression

$m_{1}=1 / N_{\max }-2 \cdot \sqrt{m_{0} \cdot m_{2}}$.

Analysis in Equation (15) makes it possible to state that when $N_{\text {max }}$ increases, the coefficient $m_{1}$ decreases to its minimum value, determined by its constituent parameters.

Thus, the decrease in the parameter values of the coefficient $m_{1}$ in Equation (14) can be considered as a reserve to increase the $\mathrm{TF}$ capacity.

\section{Coefficient $m_{2}$ study}

The value of $m_{2}$ can be evaluated using equation of the trip mileage during the mean fully developed deceleration of the TU. The equation is as follows [24, 26-27]:
$S_{s s}=V^{2} /(2 \cdot j)$

where

$S_{s s}$ - trip mileage during the mean fully developed deceleration, m;

$j$ - mean fully developed deceleration of the TU, m.s.

In here, value of $j$ is evaluated by expression:

$j=g \cdot \varphi$,

where

$g$ - gravitational acceleration, $\mathrm{m} \cdot \mathrm{s}^{-2}$;

$\varphi$ - adhesion coefficient.

The standard situation shown in Figure 7 is considered next. Two vehicles move at a certain speed; the drivers observe a safe interval equal to the linear DI (position "a"). The "leading" vehicle (number "1") begins to slow down, covers the distance $S_{s s 1}$ and stops. The stopping distance of the "driven" car (number "2") consists of two sections: the first one is covered during the driver's response and rapidity of the brake system (due to the value of $m_{1}$ ) and the second one, $S_{s s 2}$ - during the mean fully developed deceleration. Thus, the distance between the vehicles decreased to $l_{0}$ (position "b"). Besides, the situation is modeled in such a way that the deceleration value of the "leading" vehicle exceeds the same value of the "driven" one, or they are equal $\left(j_{1} \geq j_{2}\right)$. This is due to the fact that value of $L$ increases in the given conditions and it is the most relevant for safety. In this case, using Equation (16), one obtains that $S_{s s 2} \geq S_{s s 1}$. 


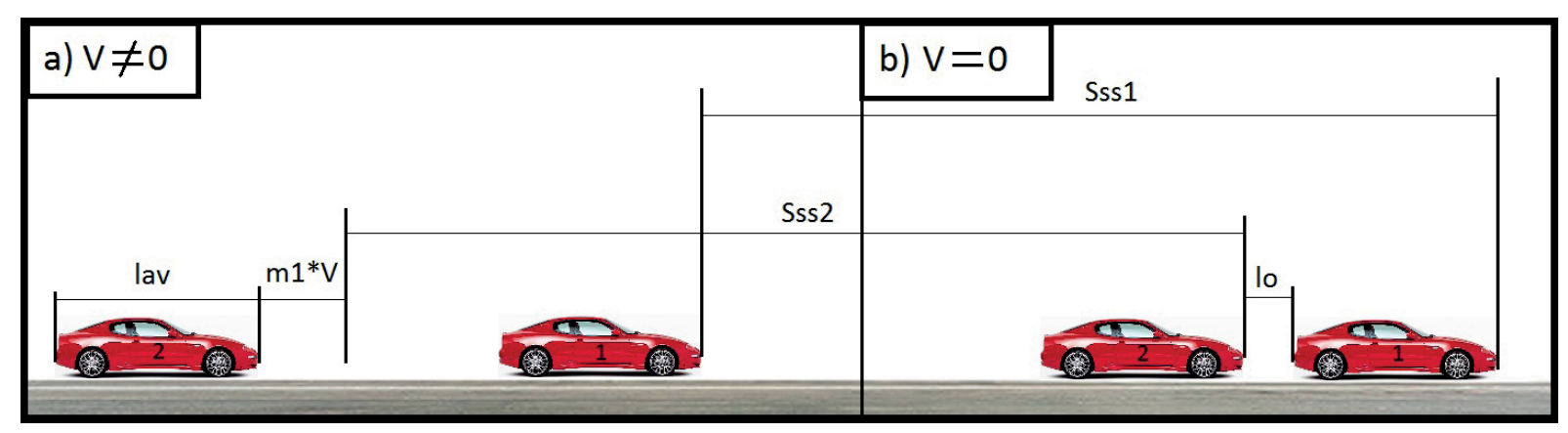

Figure 7 Interval determined between the two adjacent vehicles

Table 3 Values of adhesion coefficients and changed adherence characteristics

\begin{tabular}{|c|c|c|c|c|c|c|c|c|c|c|c|c|}
\hline \multirow{3}{*}{$\begin{array}{c}\text { order of the } \\
\text { road coverage } \\
k\end{array}$} & \multicolumn{12}{|c|}{ rank of the road coverage state $r$} \\
\hline & \multicolumn{2}{|c|}{1} & \multicolumn{2}{|c|}{2} & \multicolumn{2}{|c|}{3} & \multicolumn{2}{|c|}{4} & \multicolumn{2}{|c|}{5} & \multicolumn{2}{|c|}{6} \\
\hline & $\varphi_{20}$ & $\beta$ & $\varphi_{20}$ & $\beta$ & $\varphi_{200}$ & $\beta$ & $\varphi_{20}$ & $\beta$ & $\varphi_{20}$ & $\beta$ & $\varphi_{20}$ & $\beta$ \\
\hline 1 & 0.825 & 0.002 & 0.675 & 0.0035 & 0.425 & 0.0025 & 0.25 & 0.0025 & 0.35 & 0.0025 & 0.115 & 0.002 \\
\hline 2 & 0.825 & 0.002 & 0.55 & 0.0035 & 0.375 & 0.0025 & 0.25 & 0.0025 & 0.35 & 0.0025 & 0.115 & 0.002 \\
\hline 3 & 0.825 & 0.0035 & 0.625 & 0.0035 & 0.5 & 0.0035 & 0.25 & 0.0025 & 0.35 & 0.0025 & 0.15 & 0.002 \\
\hline 4 & 0.65 & 0.005 & 0.45 & 0.004 & 0.325 & 0.0025 & 0.21 & 0.0025 & 0.35 & 0.0025 & 0.115 & 0.002 \\
\hline
\end{tabular}

Table 4 Values of $k$ and $r$ for different types and states of the road coverage

\begin{tabular}{|c|c|c|c|}
\hline $\mathrm{k}$ & type of road coverage & $\mathrm{r}$ & state of road coverage \\
\hline 1 & cement concrete & 1 & standard dry \\
\hline \multirow{2}{*}{2} & \multirow{2}{*}{ hot asphalt concrete without rough finish } & 2 & wet clean \\
\hline & & 3 & wet dirty \\
\hline \multirow{2}{*}{3} & \multirow{2}{*}{ rough asphalt concrete } & 4 & dense snow \\
\hline & & 5 & loose snow \\
\hline 4 & cold asphalt concrete & 6 & ice crusted \\
\hline
\end{tabular}

Table 5 Results of the regression analysis $\varphi_{20}$

\begin{tabular}{|c|c|c|c|c|}
\hline \multicolumn{5}{|c|}{ regression equation: $\varphi_{20}=a_{k}-b_{k} \cdot r=a_{k} \cdot\left(1-\frac{b_{k}}{a_{k}} \cdot r\right)$} \\
\hline order k & $\mathrm{a}_{\mathrm{k}}$ & $\mathrm{b}_{\mathrm{k}}$ & $\mathrm{b}_{\mathrm{k}} / \mathrm{a}_{\mathrm{k}}$ & $\mathrm{R}^{2}$ \\
\hline 1 & 0.9300 & 0.14000 & 0.15053 & 0.9702 \\
\hline 2 & 0.8636 & 0.13128 & 0.15201 & 0.9325 \\
\hline 3 & 0.9150 & 0.13280 & 0.14513 & 0.9845 \\
\hline 4 & 0.6700 & 0.08786 & 0.13113 & 0.9024 \\
\hline
\end{tabular}

Table 6 Results of the regression analysis $\beta / \varphi_{20}$

\begin{tabular}{ccccc}
\hline & regression equation: $\beta / \varphi_{20}=A_{k} /(7-r)^{B_{k}}$ & $\mathrm{~B}_{\mathrm{k}}$ & 0.9024 \\
\hline order k & $\mathrm{A}_{\mathrm{k}}$ & 0.9449 & 0.8216 \\
2 & 0.01902 & 0.8846 & 0.9788 \\
3 & 0.01872 & 0.7492 & 0.7657 \\
4
\end{tabular}

The DI section characterized by the coefficient $m_{2}$, represents the difference

$S_{s s 2}-S_{s s 1}=\frac{V^{2}}{2 \cdot j_{2}}-\frac{V^{2}}{2 \cdot j_{1}}=V^{2}\left[\frac{j_{1}-j_{2}}{2 \cdot j_{i} \cdot j_{2}}\right]$.
Thus, $m_{2}$ can be evaluated from expression

$$
m_{2}=\frac{j_{1}-j_{2}}{2 \cdot j_{1} \cdot j_{2}}
$$




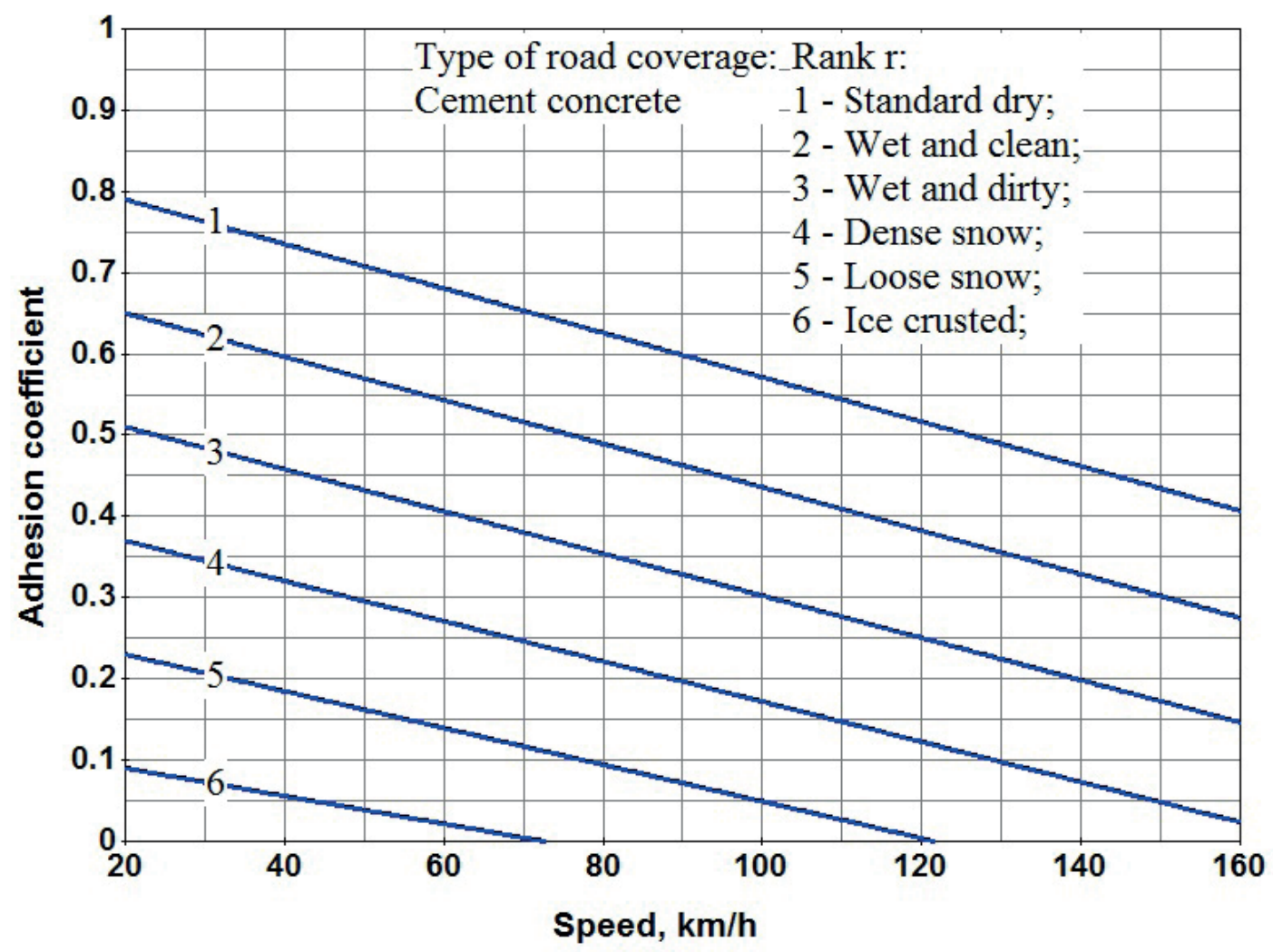

Figure 8 Adhesion coefficient versus speed

where

$j_{1}$ and $j_{2}$ - deceleration of the two adjacent vehicles, m.s. ${ }^{-2}$.

The adhesion coefficient depends on the speed, type of the road coverage and its condition, as it is shown in [29]

$$
\varphi=\varphi_{20}-\beta \cdot(V-20)=\varphi_{20} \cdot\left[1-\frac{\beta}{\varphi_{20}} \cdot(V-20)\right],
$$

\section{where}

$\varphi_{20}$ - adhesion coefficient at a speed of $20 \mathrm{~km} \cdot \mathrm{h}^{-1}$;

$\beta$ - the changed adhesion coefficient due to the speed.

In order to create a generalized assessment of $\varphi$, the data given in [29] have been used; in here, the ranges have been replaced by the average values (Table 3). Each type of the road coverage is given the order of $k$ and the state of the road coverage is ranked by $r$ (Table 4 ). The effect of the road coverage on $\varphi_{20}$ and $\beta / \varphi_{20}$ is assessed in the ordinal scale (as rank $r$ ). The regression analysis has shown that the relationship between $\varphi$ and rank $r$ is linear (Table 5) and $\beta / \varphi_{20}$ with $r$ corresponds to Zipf's law (Table 6 ). The value of $\varphi$ versus the speed on different road surfaces is illustrated in Figure 8.

Then, dependence of the adhesion coefficient on the type of the road coverage is analyzed. Structural and parametric identification of the model $\varphi$ has resulted in a generalized assessment of the adhesion coefficient, taking into account the Equation (20),

$$
\begin{aligned}
& \varphi(k, r, V)=a_{k} \cdot\left(1-\frac{b_{k}}{a_{k}} \cdot r\right) . \\
& \cdot\left[1-A_{k} /(7-r)^{B_{k}} \cdot(V-20)\right],
\end{aligned}
$$

where

$a_{k}=0.93-0.003677 \cdot \exp [1.4263 \cdot(k-1)]$; $b_{k} / a_{k}=0.152-0.0008 \cdot \exp [1.08 \cdot(k-1)]$; $A_{k}=0.0193-0.00035 \cdot \exp [0.76 \cdot(k-1)]$; $B_{k}=0.99-0.02 \cdot \exp [0.8252 \cdot(k-1)]$.

It is assumed that $\varphi$ equals to $V=20 \mathrm{~km} \cdot \mathrm{h}^{-1}$ for $V<20$ $\mathrm{km} \cdot \mathrm{h}^{-1}$.

If one takes the adhesion coefficient for the dry road coverage as a reference $(r=1)$ at $\mathrm{V}=20 \mathrm{~km} \cdot \mathrm{h}^{-1}$, then Equation (21) can be represented as

$\varphi(k, r, V)=\varphi_{s}(k) \cdot K_{\varphi}(r, V)$,

where

$\varphi_{s}$ - reference adhesion coefficient $\left(r=1, V=20 \mathrm{~km} \cdot \mathrm{h}^{-1}\right)$;

$K_{\varphi}$ - coefficient characterized by the state of road coverage and speed.

Values of $\varphi_{s}$, evaluated for each type of coverage, are given in Table 7.

When transforming expression for deceleration of the TU - Equation (17) and taking into account Equation (22), one obtains

$j=g \cdot \varphi_{s} \cdot K_{\varphi}=j_{s} \cdot K_{\varphi}$,

where

$j_{s}$ - reference deceleration of the TU $\left(r=1, V=20 \mathrm{~km} \cdot \mathrm{h}^{-1}\right)$, $\mathrm{m} . \mathrm{s}^{-2}$.

Then, substituting Equation (23) in Equation (19), one can obtain the formula to evaluate $m_{2}$, taking into account the adhesion coefficient 
Table 7 Values of $\varphi_{s}$ for different types of the road coverage

\begin{tabular}{|c|c|c|}
\hline $\mathrm{k}$ & type of coverage & $\varphi_{\mathrm{s}}$ \\
\hline 1 & cement concrete & 0.786 \\
\hline 2 & hot asphalt concrete without rough finish & 0.778 \\
\hline 3 & rough asphalt concrete & 0.742 \\
\hline 4 & cold asphalt concrete & 0.583 \\
\hline
\end{tabular}

Table 8 Performance standards for braking with brake system in operation during the road conditions management

$\mathrm{TU}$

passenger and utility vehicles

trailer cars

trucks

tractor-trailers mean fully developed deceleration of the

category of TU

$$
\mathrm{TU} \text { (min.), }
$$

$\left(\mathrm{m} . \mathrm{s}^{-2}\right)$

M1

5.8

M2, M3

5.0

M1

5.8

N1, N2, N3

5.0

N1, N2, N3

5.0

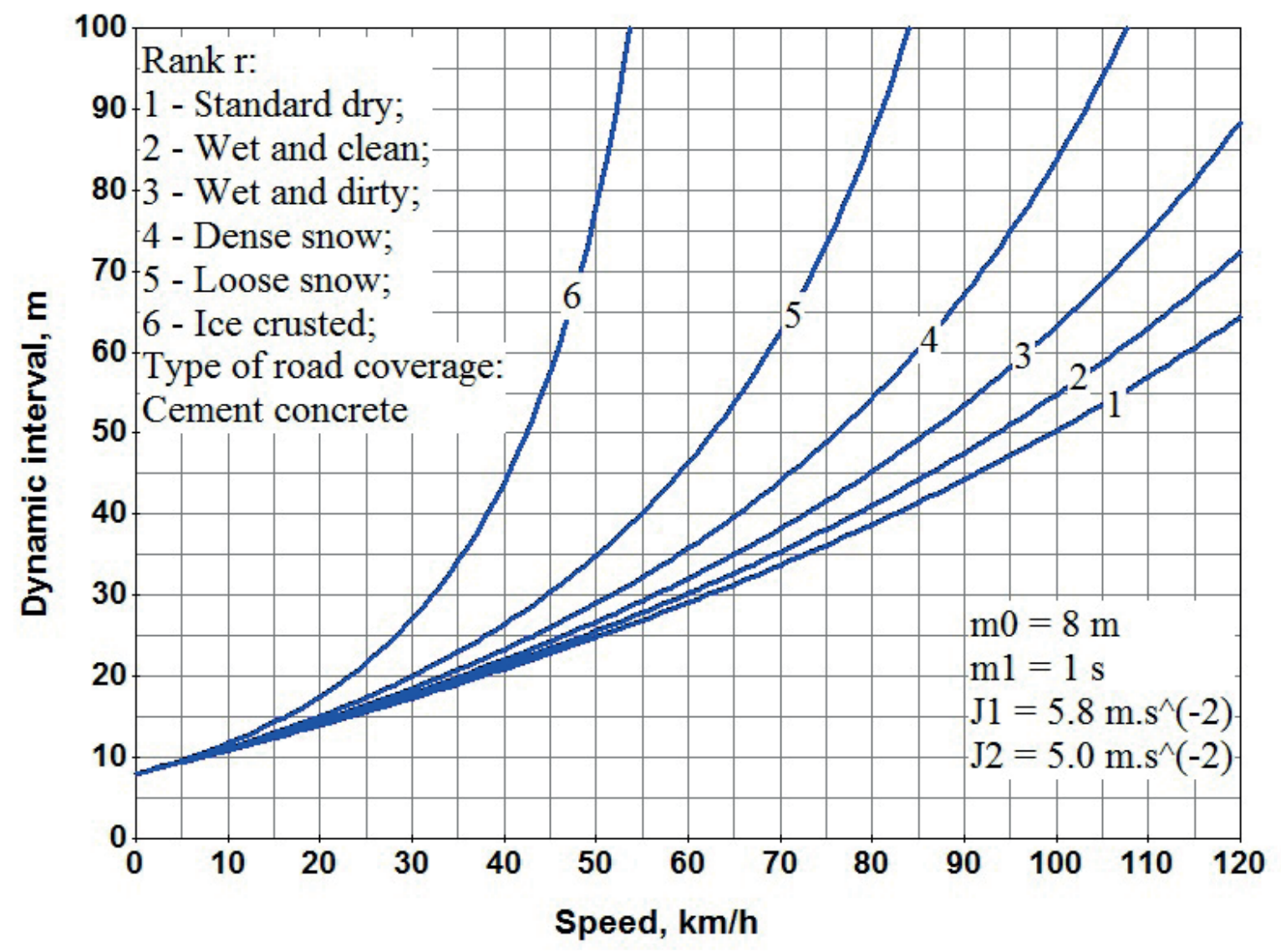

Figure 9 L versus speed under different states of the road coverage

$m_{2}=\frac{1}{K_{\varphi}} \cdot\left[\frac{j_{s 1}-j_{s 2}}{2 \cdot j_{s l} \cdot j_{s 2}}\right]=\left[\frac{\varphi_{s}}{\varphi}\right] \cdot\left[\frac{j_{s 1}-j_{s 2}}{2 \cdot j_{s l} \cdot j_{s 2}}\right]$

where $j_{s 1}$ and $j_{s 2}$ - reference deceleration of two adjacent vehicles, $\mathrm{m} . \mathrm{s}^{-2}$.

Thus, the adhesion coefficient included in Equation (24) depends on the type of the road coverage, its state and speed of the TU. Values of $j_{s 1}$ and $j_{s 2}$ depend on the structure of the TF; in here, in order to ensure safety, $j_{s 1}$ is suitable to vehicles with the greater braking efficiency in the flow and $j_{s 2}$ - with the smaller one. Values of deceleration are taken in accordance with GOST [28] for passenger vehicles of M1 and M2 categories, respectively (Table 8). 


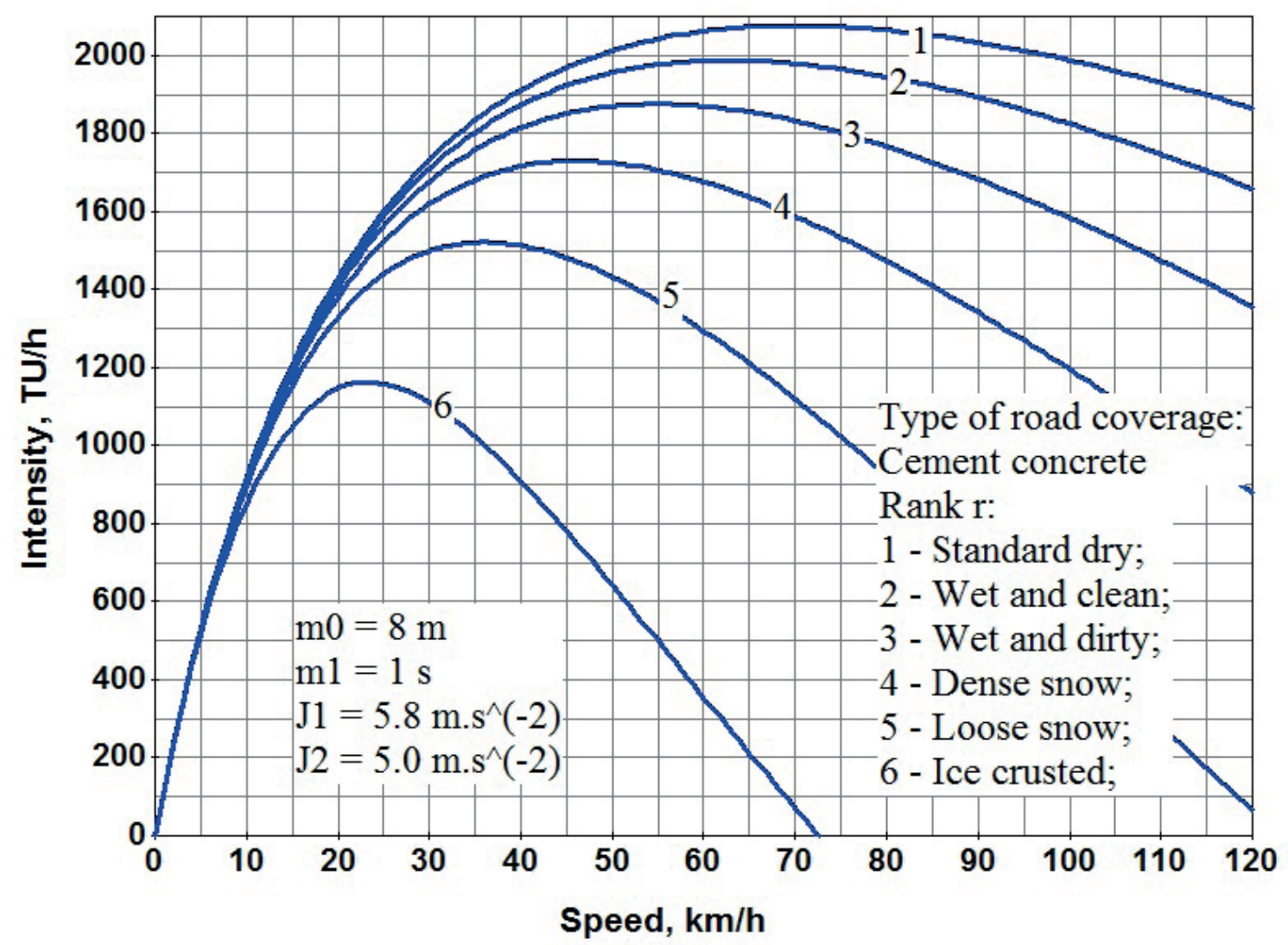

Figure $10 \mathrm{~N}$ versus speed under different states of the road coverage

6

\section{Basic models of the traffic flow}

The study has resulted in identifying the effective diagrams of the traffic flow. Dependence of the $L$ and intensity on the speed under different states of the road coverage is illustrated in Figures $9-10, m_{0}=8 \mathrm{~m}, m_{1}=1 \mathrm{~s}$ are taken in calculations.

The complete algorithmic support reflects the variability of the DI coefficients, making it possible to track the dynamics of the TF characteristics in a wide palette of travel conditions.

\section{Conclusions}

The article presents research that extends the existing mathematical representations of the linear dynamic interval model of the vehicle. The authors would like to highlight the main results (authors' contribution):

1. The method of rational choice of the interval $l_{0}$ for simulation modelling has been developed;

2. Parametric identification of the linear dynamic interval model has been performed, including a generalized estimation of the adhesion coefficient, allowing to study the dynamics of the traffic flow in various road conditions;

3. Influence of the model parameters on the traffic flow intensity has been studied.

Results are focused on development of promising engineering solutions in the field of mathematical modeling of the traffic flows and road traffic management [30]. The proposed algorithmic support is of interest to specialists involved in the problems of synthesis of the traffic safety control systems, efficiency of traffic flows and intelligent transport systems.

\section{References}

[1] DIRKS, S., KEELING, M. A vision of smarter cities: how cities can lead the way into a prosperous and sustainable future [online]. U.S.A.: IBM Corporation, 2009. Available from: https://www.ibm.com/downloads/cas/2JYLM4ZA

[2] FOSTER, M. Building and managing an intelligent city. Accenture [online]. 2011, p. 24-25. Available from: http://www.fm-house.com/wp-content/uploads/2015/01/Building-Managing-Intelligent-City.pdf

[3] HEDLUND, J. Smart city 2020: technology and society in the modern city. Microsoft Service Enterprise Architecture paper. 2012, 1, p. 12 
[4] GIFFInGER, R., FERTNER, C., KRAMAR, H., KALASEK, R., PICHLER-MILANOVIC, N., MEIJERS, E. Smart cities ranking of European medium-sized cities [online]. Final report of Centre of Regional Science in Vienna. 2007 , p. 7. Available from: http://www.smart-cities.eu/download/smart_cities_final_report.pdf

[5] NEIROTTI, P., DE MARCO, A., GAGLIANO, A., MANGANO, G., SCORANNO, F. Current trends in smart city initiatives: some stylized facts. Cities [online]. 2014, 38, p. 25-36. ISSN 0264-2751. Available from: https://doi.org/10.1016/j. cities.2013.12.010

[6] BEGICH, Y. E., SHERSTOBITOVA, P. A. The concept of smart city as a strategy to manage urban infrastructure. Construction of Unique Buildings and Structures [online]. 2017, 8(59), p. 27-40. ISSN 2304-6295. Available from: https://doi.org/10.18720/CUBS.59.2

[7] DANILOV, O. F., KOLESOV, V. I., SOROKIN, D. A. Development of criteria for transport flow efficiency assessments of the city street road network. MATEC Web of Conferences [online]. 2016, 73, 01010. ISSN 2261-236X. Available from: https://doi.org/10.1051/matecconf/20167301010

[8] DANILOV, O. F., KOLESOV, V. I., SOROKIN, D. A. Development of mathematical model for traffic flow within speed limitation. MATEC Web of Conferences [online]. 2016, 73, 01028. ISSN 2261-236X. Available from: https://doi. org/10.1051/matecconf/20167301028

[9] CHANDLER, R. E., HERMAN, R., MONTROLL, E. W. Traffic dynamics: studies in car following. Operations Research [online]. 1958, 6(2), p. 165-184. ISSN 0030-364X, eISSN 1526-5463. Available from: https://doi.org/10.1287/opre.6.2.165

[10] GAZIS, D. C., HERMAN, R., ROTHERY, R. W. Nonlinear follow-the-leader models of traffic flow. Operations Research [online]. 1961, 9(4), p. 545-567. ISSN 0030-364X, eISSN 1526-5463. Available from: https://doi.org/10.1287/opre.9.4.545

[11] DREW, D. R. Traffic flow theory and control. New York: McGraw-Hill, 1968. ISBN 978-0070178311.

[12] WIEDEMANN, R. Road traffic flow simulation / Simulation des Strassenverkehrsflusses (in German). Karlsruhe: Series of publications from the Institute of Transportation at the University of Karlsruhe / Schriftenreihe des Instituts fur Verkehrswesen der Universitat Karlsruhe, 1974. Available from: https://www.worldcat.org/title/simulationdes-straenverkehrsflusses/oclc/634105860

[13] GIPPS, P. G. A behavioural car-following model for computer simulation. Transportation Research Part B: Methodological [online]. 1981, 15(2), p. 105-111. ISSN 0191-2615. Available from: https://doi.org/10.1016/01912615(81)90037-0

[14] FRITZSCHE, H. T. A model for traffic simulation. Traffic Engineering and Control. 1994, 35(5), p. 317-321. ISSN 0041-0683. ISSN 0041-0683.

[15] SEARLE, J. Equations for speed, time and distance for vehicles under maximum acceleration. In: Safety Technology session of the 1999 SAE International Congress and Exposition and is included in the SAE Special Publication, "Advances in Safety Technology 1999" (SP-1433): proceedings. Society of Automotive Engineers. 1999. ISBN 0768003652, p. 1-11.

[16] TREIBER, M., HENNECKE, A., HELBING, D. Congested traffic states in empirical observations and microscopic simulations. Physical Review E [online]. 2000, 62(2), 1805. ISSN 2470-0045, eISSN 2470-0053. Available from: https://doi.org/10.1103/PhysRevE.62.1805

[17] JIANG, R., WU, Q., ZHU, Z. Full velocity difference model for a car-following theory. Physical Review E [online]. 2001, 64(1), 017101. ISSN 2470-0045, eISSN 2470-0053. Available from: https://doi.org/10.1103/PhysRevE.64.017101

[18] NEWELL, G. F. A simplified car-following theory: a lower order model. Transportation Research Part B: Methodological [online]. 2002, 36(3), p. 195-205. ISSN 0191-2615. Available from: https://doi.org/10.1016/S0191-2615(00)00044-8

[19] OLSTAM, J. J., TAPANI, A. Comparison of car-following models [online]. Swedish National Road and Transport Research Institute, 2004. Available from: https://www.researchgate.net/publication/265198439_Comparison_of_Carfollowing_models

[20] RAKHA, H. Validation of Van Aerde's simplified steady state car-following and traffic stream model. Transportation Letters - The International Journal of Transportation Research [online]. 2009, 1(3), p. 227-244. ISSN 1942-7867, eISSN 1942-7875. Available from: https://doi.org/10.3328/TL.2009.01.03.227-244

[21] INOSE, H., HAMADA, T. Traffic management. Moscow: Transport, 1983.

[22] GASNIKOV, A. V. Introduction to mathematical modeling of traffic flows. Moscow: MIPT, 2010. ISBN 978-5-7417-0334-2.

[23] NATHAN, G., CARROLL, J., AJAY, K. Traffic flow theory: a state of the art report [online]. Washington DC, 2001. Available from: https://www.academia.edu/39779635/Traffic_Flow_Theory_A_State-of-the-Art_Report

[24] PUGACHEV, I. N., GOREV, A. E., OLESHENKO, E. M. Organization of road traffic and traffic safety. manual for graduate students. Moscow: Academia Publishing House, 2009. ISBN 978-5-7695-4662-4.

[25] SOTSKOV, D. A., NUZHDIN, R. V., KUNAKOV, A. P., NAZAROV, A. G. Modeling of emergency brake application in traffic flow [online]. Analytical and expert support for road traffic safety system: collection of reports. St. Petersburg: GASU, 2006, p. 16-21. Available from: http://www.adf.spbgasu.ru/Conference2006/section_4.pdf

[26] GUDKOV, V. A. Safety of transport units (vehicles). Manual for graduate students. Moscow: Hotline - Telecom, 2010. ISBN 978-5-9912-0090-5. 
[27] BAKHTINA, O. N. Study on characteristics of traffic flow in conditions prior to traffic congestion [online]. Organization of road traffic and traffic safety in large cities: collection of reports. St. Petersburg: GASU, 2008, p. 168-171. Available from: http://lib.madi.ru/fel/fel1/fel10B008.pdf

[28] GOST R 51709 Motor vehicles. Safety requirements for technical condition and verification methods [online]. Introduced 2002-01-01. Moscow: Publishing House of Standards, 2001. Available from: http://docs.cntd.ru/document/ gost-r-51709-2001

[29] VASILIEV, A. P. Reference encyclopedia of a road builder. Book 2. Repair and maintenance of roads [online]. Moscow, 2004. Available from: http://science.totalarch.com/book/0502.rar

[30] KAPSKI, D., KASYANIK, V., LOBASHOV, O., VOLYNETS, A., KAPTSEVICH, O., GALKIN, A. Estimating the parameters of traffic flows on the basis of processing of localization data on the movement of vehicles. Communications - Scientific Letters of the University of Zilina [online]. 2019, 21(2), p. 89-99. ISSN 1335-4205, eISSN 2585-7878. Available from: http://komunikacie.uniza.sk/index.php/communications/article/view/1474 